\title{
Performance Evaluation of Sheltered Workshops. Does Legal Status Matter?
}

\author{
María-Celia López-Penabad ${ }^{1, *}{ }^{\circledR}$, José Manuel Maside-Sanfiz ${ }^{1}\left(\mathbb{0}\right.$, Juan Torrelles-Manent ${ }^{2}$ \\ and Carmen López-Andión ${ }^{3}(1)$
}

1 Department of Financial Economics and Accounting, Faculty of Economics and Business Administration, USC, 15782 Santiago de Compostela, Spain; josemanuel.maside@usc.es

2 Faculty of Economics and Business Administration, University of Santiago de Compostela, 15782 Santiago de Compostela, Spain; juan.torrelles@rai.usc.es

3 Department of Quantitative Economics, Faculty of Economics and Business Administration, USC, 15782 Santiago de Compostela, Spain; carmen.lopez.andion@usc.es

* Correspondence: celia.lopez@usc.es; Tel.: +34-881811626

Citation: López-Penabad, M.-C.;

Maside-Sanfiz, J.M.; Torrelles-Manent, J.; López-Andión, C. Performance Evaluation of Sheltered Workshops. Does Legal Status Matter?. Sustainability 2021, 13, 1100. https: / doi.org/10.3390/su13031100

Academic Editor: Madalina

Ecaterina Popescu

Received: 23 November 2020

Accepted: 18 January 2021

Published: 21 January 2021

Publisher's Note: MDPI stays neutral with regard to jurisdictional claims in published maps and institutional affiliations.

Copyright: (c) 2021 by the authors. Licensee MDPI, Basel, Switzerland. This article is an open access article distributed under the terms and conditions of the Creative Commons Attribution (CC BY) license (https:/ / creativecommons.org/licenses/by/ $4.0 /)$.

\begin{abstract}
Social enterprise pursues both social and economic goals and is recognized as a formula for achieving sustainable development. Sheltered workshops (SWs) are a manifestation of this phenomenon, their main objective being the labor market integration of disabled people. In this paper, the efficiency of SWs has been studied taking into account the operational and the core social aspects, as well as their distinct nature, namely for-profit or non-profit status. Additionally, we have analyzed the relationship between the social efficiency and the economic returns of these entities. To do this, a semiparametric methodology, combining different data envelopment analysis (DEA) models with truncated regression estimation has been used. It is the non-profit and top-performing SWs that achieve the best social and economic efficiency. For-profit and low-performing SWs show further reductions in social efficiency as a result of the economic crisis and uncertainty in subsidyrelated public policies. Their extensive social proactiveness and high economic strength in the crisis period positively influenced their social and economic efficiency. We have also proven that it is the most profitable SWs that have the greatest social efficiency. We consider that our results constitute a useful complement to other evaluation models for social enterprise.
\end{abstract}

Keywords: disadvantaged employees; performance; social enterprise; sheltered workshops; DEA

\section{Introduction}

Although there is no unanimous agreement on what social enterprise (SE) means, different institutions and authors have developed their own definitions. Most of them concur that such companies can be labelled "hybrid organizations" with a social agenda and incorporate the presence of the market as a source of funding so that they have enough capital to invest in their projects [1]. In spite of their categorization as hybrid companies, SEs can differ in terms of the importance that they attribute to economic logic and social logic, with the creation of social value always taking preference over financial performance [2,3].

This paper has studied one type of SE that is very common throughout the world, sheltered workshops (SWs), which employ a unique longitudinal dataset consisting of the entire list of sheltered workshops in Galicia (Spain) from 2008 to 2017.

SEs make a valuable contribution to today's labour markets, tackling problems such as unemployment and the social exclusion of vulnerable groups and thus play a role in sustainable economic growth. This is related to Agenda 2020, goal 8, promoted by United Nations. Specifically, SWs perform an important function in society by creating social value, since they are companies one of whose objectives is to help workers with disabilities find remunerated work placements which fit their skills profile. Secondly, they help them integrate into the world of ordinary work by way of essential personal 
adjustment and social services (such as counselling and healthcare, rehabilitation, and training). Moreover, they develop economic activities by producing and selling goods or services with market-based methods that provide them with financial resources to support their social mission.

As a result, they face a dilemma regarding whether to assign their resources to social activities to generate social value or to commercial activities to provide products and services at competitive prices and quality, which can reduce the efficiency of the company.

This takes place in a changing environment for SWs where they receive fewer government subsidies but at the same time demonstrate greater professionalization due to the state demanding higher standards in order for them to be eligible for benefits and to be able to compete.

These aspects have led to the need for SEs, and, in particular for SWs, not only to report their economic and financial situation but also their ability to meet their social objectives [4-6], which, in turn, helps us work out whether the models which the SEs provide are feasible and able to cope with periods of economic downturns or cuts to benefits and grants.

A considerable number of papers on SEs center on their economic value, partly due to data availability, but try to steer clear of social value which is often difficult to quantify due to it being an abstract concept. In this study, we have analyzed the performance of these social companies from an efficiency point of view, trying to incorporate both aspects in the analysis of them.

Understanding how SEs perform is complicated owing to their hybrid nature. SWs have a financial and a social role and need to be efficient at both. We have tried to measure the efficiency of SWs in relation to financial and social aspects due to their important role in integrating people with disabilities as well as their reliance on the public aid they receive. The lack of information on their performance can raise doubts about their effectiveness in fulfilling their mission, both in the case of SWs and the SE in general.

In order to obtain reliable results, all the elements involved in the organization's social activities need to be thoroughly examined. A broad definition of social goals should include their impact on the local community, the environment, society as a whole and staff. When evaluating a large number of SEs, this approach does not provide the outputs necessary to make a consistent comparative analysis and it is necessary to advance in a simpler data collection model. This is the reason why we have used data from annual accounts for the analysis of economic efficiency in addition to incorporating two indicators of SW distinctive social principles provided by public administrations: the number of disadvantaged employees and the support unit subsidies (SUS) that provide personal adjustment and social services to workers with disabilities. We are aware that this is a limited vision of their social performance, but we believe that this measure is justified since these social outputs are one of the main factors for assessing SWs' social contribution.

The lack of standardized values and the scarce availability of data for this type of company, have forced us to take the quantifiable indicators which are available for the whole sample as measures of social value. We have prioritized valuing as many SWs as possible rather than focusing on comprehensively obtaining the social value of a small number of SWs. This decision has allowed us to carry out a more statistically robust analysis. The limitation should be considered bearing in mind that the result may not reflect the full social value generated by SWs, nevertheless it can be very useful if it is applied prior to a detailed analysis using other quantitative and qualitative factors.

A major part of this work is that, firstly, it offers empirical evidence, allowing us to evaluate the performance of SWs. Data envelopment analysis (DEA) has been applied using both operational and social indicators, aspects that have hardly been considered to date. Secondly, it covers a broad time horizon, exploring the evolution of SW efficiency in the 2008-2013 Credit Crunch and the resultant economic recovery period of 2014-2017. Have SWs been able to improve in terms of social and economic efficiency since the end of said financial crisis? Thirdly, it must be pointed out that in Galicia, nearly all SWs 
are privately-owned, but are all either for-profit legal entities or not-for-profit legal ones. Whether the legal form they adopt affects their efficiency has been examined. Fourthly, we have considered how social and economic performance are related. In order for this to be done at the methodological level, we have applied a two-step procedure with a double bootstrap proposed by Simar and Wilson [7], which has allowed us to obtain more robust and reliable results than if we were to use the traditional techniques.

The article has been set out with the following structure: In the second section we analyze the concept of SW and performance measurement of SE, going on to review earlier literature, many of which is widely read in SWs in order for them to learn how social and economic efficiency go hand in hand. In the third section, we present the data and methodology applied (DEA) with the explanation of the inputs/outputs employed. The penultimate part explains the results of the empirical analysis with respect to temporal evolution and the effect of legal form (i.e., NPL and FPL) on efficiency, not only overall, but also economically and socially, finishing off by offering an analysis of this relationship. Finally, our conclusions are based on the present state of the companies, thus allowing us to better understand the process of creating value.

\section{Literature Review}

In the EU by and large, and particularly in Spain, the disabled are employed far less than the able-bodied, resulting in higher unemployment rates $[8,9]$.

Disabled people can be recruited for ordinary employment (i.e., working for the state or for companies) and protected employment (SW) or be self-employed. In this country of late, more and more contracts have been given to people with disabilities, due in part to there being more job opportunities in SWs, with a clear rise in protected employment as opposed to ordinary work.

From a legal point of view, SWs in Spain are part of the Social Economy and can be defined as companies whose specific objective is to provide those with special needs with a job that allows them to become settled in the standard job market (Law 5/2011, of 29 March, on Spanish Social Economy). SWs are companies where at least $70 \%$ of workers are disabled and carry a declaration stating that their degree of disability is equal to or greater than 33\% (art. 43 Royal Decree 1/2013 of 29 November).

The status of SWs in Spain is at variance when it comes to the fact that they can be considered either for-profit legal (FPL) or not-for-profit legal (NPL). Although, legally, both types of SWs are considered social economy companies in our country, for-profit legal SWs do not comply with some of their principles of inspiration and should not be considered SEs [10]. To be an SE, the social mission must prevail over profit, as contemplated by the approach proposed by EMES, a European Research Network [11].

In order for both types of entities to receive significant government benefits that are allocated to their budgets, they must prove their efficiency and clarify how much they are affected by their distinct economic and social orientation. For NPL SWs, profits are reinvested in the social mission and their predominant focus is on creating social value; nonetheless, FPL SWs are more focused on profit maximization, which is subsequently shared among their shareholders.

The traditional vision of an SE has been that of an organization which strikes the balance between social performance and economic performance, highlighting the challenges it faces in trying to achieve both aims simultaneously [12] and meeting the demands of stakeholders [13]. The social impact and economic results are considered the results of different processes $[13,14]$, and entail solving "a problem", trying to reach agreements that prevent reciprocal damage [15]. What this means is that if companies fail to align their objectives, the literature on hybrid companies warns of the risk of mission drift, i.e., the separation of the planned objectives in the social field, as a result of economic objectives being put first [16].

Other authors have presented SEs as an example of shared value because they need to achieve both objectives simultaneously with a view to integration rather than confrontation 
of both aspects [17]. It is possible to gain enough profit for shareholders without destroying social value, taking into account the interests of the different stakeholders [12] and that SEs can perform better due to having a hybrid status at their core [1]. If hybrid organizations manage to make an impression on the different stakeholders when developing their social role, they will improve their legitimacy and reputation, not to mention their performance in the product market, and consequently in their financial performance [2].

In any case, the economic aspects are necessary so that the SEs can be sustainable [18]. Economic prosperity is a necessary condition for satisfactory social contribution to be sustainably developed $[19,20]$ while economic efficiency is seen as a facilitator for gaining social efficiency [21]. SEs are able to place greater emphasis on their social objectives once they have managed to achieve a good enough economic performance to free up resources for them $[12,22,23]$.

As a result, different authors have pointed out the importance of developing information and measurement systems that recognize this double objective $[6,16,24]$.

Although there is plenty of literature on performance measurement for SEs, this is, in many cases, qualitative, and descriptive. Many of these studies are purely conceptual discussions or applications to one particular company. Although there are methods which are more commonly used than others, due to the complexity of the process itself (i.e., the diversity of the social phenomenon, multicausality and the demands of stakeholders), none of them have become recognized as the standard [25]. This means that social impact measurement is scarce and studies referring to the term SE tend to just analyze cases where there is heterogeneity [3].

While these approaches are useful tools for managing individual organizations, the data needed to perform comparative analyses with different SEs are not often available nor do they allow the theory to be properly tested by statistical analysis [17].

SE quantitative research remains scarce. A large part of SE-related empirical research has focused on case studies with a limited number of enterprises, which has clearly provided important knowledge on the subject, but has meant that understanding it on a large scale as well as discovering the actual effects of SEs in society carries limitations [3]. The development of statistically robust national and international analyses on how SEs perform at a social level has become a top priority [26].

One part of the empirical work available on SEs and especially on SWs in Spain, has focused on their economic and financial situation via ratio analysis [10,27-30]. Even though the geographic scope, time period and measurements used are not homogenous in general, it has concluded that most of the SWs are small companies and belong to the service sector. They have high levels of solvency and liquidity, which has allowed them to survive in the market in spite of making little profit. In addition, it signals that not-for-profit legal SWs obtain lower returns (ROE and ROA) than for-profit legal ones, although it is always positive.

Another series of investigations has analyzed how both social value and economic value are generated and, normally upholds that social and economic goals go hand in hand. For instance, Spieth et al. [31] conducted qualitative research on 17 German social businesses and highlighted that economic profits enabled their social missions and, similarly, that social benefits created positive economic returns. They also indicated that the priority of social businesses was to create social value rather than economic returns.

We move on to take a look at the few studies that have analyzed these aspects for SWs or similar SEs by focusing on the provision of employment to vulnerable social groups.

Bellostas et al. [18] studied a group of Spanish SWs and signalled that social and economic worth are created, thus implying that there is a tight bond between them. The economic value is a result of the social value generated, which is the primary objective of SWs, but the relationship is not bidirectional since economic returns do not generate high levels of social value by themselves.

Battilana et al. [12] examined the elements that affect social performance in a set of WISEs (work integration social enterprises), organizations similar to SWs and found that 
social imprinting and making profit are both linked to the successful application of their social mission.

Other studies have analyzed value creation by calculating efficiency scores using DEA models. Staessens, et al. [17] applied this methodology in order to analyze how much priority is given to social and economic aspects, and their effects on efficiency for a set of Flemish SWs (2004-2013), signalling different types of mission drift. Enterprises with strong economic orientation are more economically and socially efficient and show a mission drift which goes against expectations; paying more attention to economic objectives does not necessarily cause a reduction in social performance. The other side of the coin, however, is that those who focus more on their social objectives do not have high social efficiency due to their low economic efficiency.

Lee and Seo [19] studied the efficiency of SEs in terms of job-creation for vulnerable social groups in Korea applying a DEA so as to take into account both operational performance and social values. They incorporated grants under the term "dual-role factor", considering them an input because they supply financial resources, and as an output due to the reception of them being performance-related. They concluded that subsidies perform different roles in SE performance in accordance with their longevity. The oldest companies do everything they can to reduce the amount given to them while the newest try to receive more of them. Finally, they performed an efficiency analysis by sector in order to provide benchmarks for enterprises in the same field of business.

As for the influence of social orientation on SE performance, the results have been unclear. Gali et al. [2] performed an empirical study based on a questionnaire to a sample of Austrian companies. Although greater social orientation directly leads to greater social performance, which in turn has a positive (indirect) effect on financial performance, conversely, the higher the social orientation the higher the negative effect is on financial performance. In other words, both effects cancel each other out, meaning that the higher the social orientation, the better the social performance, while the financial performance is no higher.

We consider that NPL SWs have a greater social orientation than FPL SWs, although we are unaware of any previous studies whereby being a not-for-profit organisation or a profit-seeking one are considered determinants in terms of efficiency. There are other bodies of research which have studied these aspects in other types of SEs even though results are mixed. Battilana et al. [12] pointed out that for WISEs the not-for-profit status only has a slight effect on social performance and economic productivity is often unexpectedly lesser. Gutiérrez-Nieto et al. [32] asserted that NGOs are more efficient socially than microfinance institutions that operate under other legal structures.

As SEs, especially SWs, have only started to be researched relatively recently, there is a lack of earlier studies assessing social efficiency and financial efficiency individually by way of a dual-goal approach.

\section{Methodology}

\subsection{Data Envelopment Analysis}

Previous papers have used a number of parametric and non-parametric techniques in order to measure efficiency. The data envelopment analysis (DEA), devised by Charnes et al. [33], as well as similar ones like the Malmquist productivity index are noteworthy non-parametric techniques used to estimate how efficiently inputs are transformed into outputs via the production possibilities frontier.

DEA is widely utilized for public sector evaluations and non-profit organizations when it is difficult to access information regarding prices and is particularly useful when there is no desire for the DMUs (decision making units) analyzed to maximize profits, such as in healthcare, education and public administration units [34]. In addition to this, DEA is used with multi-objective areas like corporate social responsibility, environmental performance and sustainable development, eco-efficiency and circular economy, microfinance and 
foundations and those already mentioned by Staessens et al. [17] and Lee and Seo [19], who looked into job-creation for vulnerable groups in SEs.

In practice there are no clear guidelines on how to choose the most suitable DEA model. Taking different aspects into account results in several models: static (BCC, CCR, SBM, etc.) or dynamic (Malmquist productivity index or similar), types of returns (constants to scale, variable to scale) or their orientation (input, output, not oriented) [35]. In the next section, we group the different models used in our analysis together.

\subsubsection{Static Models: CCR and BCC Models, Scale Efficiency, and SBM Model CCR and BCC Models}

There are many DEA models, starting with basic versions which are becoming more and more popular. For instance, two of them, namely CCR [33] and BCC [36] use calculations by way of radial efficiency, with the former assuming constant returns to scale and the latter variable ones. The variable model considers the efficiency ratio of each DMU which is subsequently calculated and contrasted against other efficient DMUs with a similar scale.

DEA models are designed with input or output orientation. They can be distinguished thanks to the adjustment of inefficient units which achieve efficient projections. We have used an output orientation in our model since SWs aim to maximize their performance, both economically and socially, for a given level of productive factors or inputs.

If $n$ is the number of DMUs, $q$ is the number of outputs that $i$ produces, $Y_{i}=\left\{y_{r i}\right\}$, and $p$ is the number of inputs that $i$ consumes, $X_{i}=\left\{x_{j i}\right\}$.

The CCR output-oriented model is as follows: Max $\varnothing_{0}$

$$
\begin{gathered}
\text { s.t. }: \sum_{i=1}^{n} \lambda_{i} x_{j i} \leq x_{j 0} \quad j=1, \ldots, p \\
\sum_{i=1}^{n} \lambda_{i} y_{r i} \geq \varnothing_{0} y_{r 0} \quad r=1, \ldots, q \\
\lambda_{i} \geq 0 \quad i=1, \ldots, n
\end{gathered}
$$

where $\varnothing$ is the technical efficiency score and $\lambda$ is the weight assigned to inputs and outputs. We can obtain the BCC model by adding the following constraint to the preceding CCR model:

$$
\sum_{i=1}^{n} \lambda_{i}=1
$$

DMUs which hit maximum scores are awarded a value equal to 1 , or $100 \%$, depending on the scale used. The closer they are to the unit, the more efficient a company is.

\section{Scale Efficiency}

When efficiency levels obtained in the CCR and BCC models are compared, we can analyze scale efficiency. The global technical efficiency (TE) of a given SW is obtained by applying the CCR model, while the BCC model obtains what is known as pure technical efficiency (PTE) because it considers performance levels compared to virtual SWs with similar dimensions. If there is a difference between CCR and BCC scores for a DMU, it indicates that there is scale inefficiency.

Mathematically, the scale efficiency score is obtained by dividing the TE score by the PTE score [36].

$$
\begin{gathered}
\mathrm{SE}=\mathrm{TE} / \mathrm{PTE} \\
\mathrm{TE}(\mathrm{CCR})=\mathrm{PTE}(\mathrm{BCC}) \times \mathrm{SE}
\end{gathered}
$$




\section{The SBM Model}

The SBM (slack based measure) model devised by Tone [37], unlike traditional models, is a non-radial model which takes the individual deviations that each input and output produces into consideration and recognizes the non-proportional nature of performance deterioration that can occur in the real world.

Here is how the SBM model (output orientated) is formulated:

$$
\frac{1}{\rho_{0}^{*}}=\operatorname{Max} 1+\frac{1}{q} \sum_{r=1}^{q} \frac{S_{r}^{+}}{y_{r 0}}
$$

Subject to:

$$
\begin{gathered}
x_{j 0}=\sum_{i=1}^{n} \lambda_{i} x_{j i}+S_{j}^{-} \\
y_{r 0}=\sum_{i=1}^{n} \lambda_{i} y_{r i}-S_{r}^{+} \\
\lambda_{i} \geq 0, S_{j}^{-} \geq 0, S_{r}^{+} \geq 0, r=1, \ldots, q, j=1 \ldots \ldots m
\end{gathered}
$$

where $S^{-}$represents excess input and $S^{+}$means output shortfall, or slack.

\subsubsection{The Dynamic Model: The Malmquist Productivity Index}

The evolution of efficiency that we have seen in the previous models does not take into account movements that can occur at the border of good practices between different periods. We cannot see whether an alteration in efficiency is caused by changed performance in the DMU itself, or an adjustment in the border [38].

To measure productivity changes over time it is necessary to supplement the efficiency scores obtained from the DEA with the result given by the Malmquist productivity index (MPI), breaking down the total factor productivity (TFP) into two components: the movement of the efficient frontier (frontier-shift), or the technical change (TC) and the technical efficiency change (TEC) from the DMU analyzed in the timeframes under study (catching-up).

This is as follows:

$$
\mathrm{TFP}=\mathrm{TEC} \times \mathrm{TC}
$$

TFP $<1$ means a fall in total productivity, TFP 1 means that there is no variation in total productivity, and TFP $>1$ indicates a rise in total productivity. TEC and TC can take values greater than, less than or equal to 1 and are interpreted in a similar way to TFP.

\subsection{The Parametric Complementary Approach}

Once the different analyses discussed above were carried out and so as to determine the connection between social and economic efficiencies, we proposed using a parametric analysis by way of a truncated regression estimation with double-bootstrap. To do this we applied Algorithm II by Simar and Wilson [7] which gave us the possibility of receiving more trustworthy and sound data than the more traditional and typically employed techniques for investigations of this caliber (such as OLS and Tobit).

We estimate truncated regression with the following model:

$$
\hat{\hat{\phi}}_{i t}=\beta_{0}+\beta_{1} Z_{i t}+\varepsilon_{i t} \mathrm{i}=1,2, \ldots, n \quad t=1, \ldots, T
$$

where $\hat{\widehat{\varnothing}}_{i t}$ refers to the corrected efficiency scores obtained by the SW $i$ in period $t$ (the bootstrapped bias-corrected efficiency score), $\beta_{0}$ and $\beta_{1}$ are the parameters to be estimated, $Z_{i t}$ is the variable which tends to clarify the reason for the variation in effectiveness and $\varepsilon_{i t}$ is an error term which is truncated and normally distributed (zero mean and $\sigma_{\varepsilon}^{2}$ variance with left-tail truncation). 


\subsection{Variables and Data. Selecting and Measuring Input and Output}

In our study, we have given the output based on the social and economic variables, and the inputs reflect the resources available to a company for meeting social and economic goals. Since our intention is to discover whether SWs achieve sufficient objectives in social and economic aspects, or even improve upon them, choosing a model with output orientation seems more appropriate.

\subsubsection{Description of Variables}

A significant number of DEA models use data from annual accounts as inputs and outputs to measure economic efficiency [35]. Even though several social impact value models have been suggested $[39,40]$, measuring social value is more complicated due to the lack of standard values [41].

In line with the literature we have selected three inputs: investments in tangible fixed assets, operating costs and salary cost subsidies.

As an economic output, we have used a classic measure, namely net revenue. SWs are enterprises whose goal is to provide work for persons with disabilities and the necessary personal and social adjustment services. In this sense, the social output has been worked out in accordance with how many disabled staff were at the company and the support unit subsidies paid in.

\subsubsection{Input Variables}

Fixed tangible asset (FTA) represents operating assets, or property, plant, and equipment. Other similar papers have taken this variable as an input [17,42].

Salary cost subsidies (SCS) is a variable related to grants received based on the number of workers with disabilities hired. Numerous papers have used this variable in the application of DEA models in the non-profit sector $[43,44]$ or in SEs with job creation for vulnerable groups $[17,19]$.

Operating costs (OC) includes expenses related to operations: the cost of sales, salaries and wages, depreciation, and other expenses. Other research papers have taken this variable to be an input in DEA models $[17,45,46]$.

\subsubsection{Output Variables}

Net revenue (NR) is defined as a company's sales of goods or services $[17,19,45,46]$.

The number of disadvantaged employees in work is represented by the initials DE. The main objective of SWs is to supply the disabled with remunerated work. Staessens et al. [17], among others, have used this output in order to research SWs, while Battilana et al. [12] and Retolaza et al. [42] have carried out theirs for the previously-mentioned work integration social enterprises (WISEs).

Support unit subsidies (SUS) aim to provide personal adjustment and social services to workers with disabilities. Battilana et al. [12] used this type of grant to measure the social performance of French WISEs.

Detailed data which includes inputs and outputs are provided in Table 1 for the period 2008-2017. We have gathered financial data from annual accounts (the SABI database) and the rest of the data have been provided by the Galician Department of Economy, Employment and Industry. Our database comprises 610 observations (206 related to NPL and 404 to FPL) from 2008 to 2017, with varying numbers of SWs in each of the years studied. 
Table 1. Inputs and Outputs-Statistical summary (2008-2017).

\begin{tabular}{|c|c|c|c|c|c|c|}
\hline & \multicolumn{3}{|c|}{ Inputs } & \multicolumn{3}{|c|}{ Outputs } \\
\hline & FTA & OC & SCS & NR & $\mathrm{DE}$ & SUS \\
\hline \multicolumn{7}{|l|}{ Mean } \\
\hline All & $454,558.94$ & $748,889.57$ & $91,810.79$ & $678,153.85$ & 23.44 & 5425.87 \\
\hline NPL & $840,970.88$ & $1,236,102.02$ & $166,890.35$ & $1,103,941.1$ & 39.67 & $11,504.71$ \\
\hline FPL & $257,248.71$ & $503,112.57$ & $53,900.96$ & $463,164.18$ & 15.25 & 2312.84 \\
\hline \multicolumn{7}{|l|}{ SD } \\
\hline All & $1,131,706.93$ & $1,129,725.06$ & $150,899.83$ & $1,078,732.67$ & 34.01 & $20,145.76$ \\
\hline NPL & $1,586,445.71$ & $1,615,032.46$ & $227,416.29$ & $1,544,218.91$ & 49.34 & $32,018.05$ \\
\hline FPL & $732,584.49$ & $647,796.62$ & $61,481.34$ & $636,709.61$ & 17.55 & 7892.41 \\
\hline \multicolumn{7}{|c|}{ Median } \\
\hline All & $69,691.69$ & $338,598.19$ & $41,403.25$ & $301,139.59$ & 12.00 & 0 \\
\hline NPL & $215,431.70$ & $590,089.52$ & $53,859.88$ & $486,665.41$ & 14.00 & 0 \\
\hline FPL & $39,896.70$ & $229,387.63$ & $31,805.47$ & $176,784.43$ & 10.00 & 0 \\
\hline \multicolumn{7}{|l|}{ Min } \\
\hline All & 0 & 3724.01 & 313.75 & 0 & 0.50 & 0 \\
\hline NPL & 0 & $11,003.67$ & 1023.05 & $10,649.72$ & 1.00 & 0 \\
\hline FPL & 0 & 3724.01 & 313.75 & 0 & 0.50 & 0 \\
\hline \multicolumn{7}{|l|}{ Max } \\
\hline All & $7,424,616.80$ & $8,003,012.69$ & $1,340,483.37$ & $8,253,007.25$ & 218.00 & $212,627.70$ \\
\hline NPL & $7,424,616.80$ & $8,003,012.69$ & $1,340,483.37$ & $8,253,007.25$ & 218.00 & $212,627.70$ \\
\hline FPL & $5,374,580.01$ & $3,595,581.4$ & $432,015.86$ & $3,556,687.45$ & 163.00 & $62,009.35$ \\
\hline \multicolumn{7}{|l|}{ No. } \\
\hline All & 610 & 610 & 610 & 610 & 610 & 610 \\
\hline \multicolumn{7}{|l|}{ All } \\
\hline \multicolumn{7}{|l|}{ All } \\
\hline NPL & 206 & 206 & 206 & 206 & 206 & 206 \\
\hline FPL & 404 & 404 & 404 & 404 & 404 & 404 \\
\hline
\end{tabular}

Source: own elaboration.

\section{Empirical Results}

4.1. Comparative Analysis Efficiency; NPL and FPL SWs

Table 2 lists the efficiency values for the different models used: technical efficiency (CCR), pure technical efficiency (BCC), scale efficiency (CCR/BCC), SBM-BCC, SBM-CCR, social efficiency $(\mathrm{BCC})$, economic efficiency $(\mathrm{BCC})$, total factor productivity (TFP-BCC), technical efficiency change (TEC-BCC), and technical change (TC-BCC). These are shown with both mean and median for SWs, differentiated by NPL and FPL subsamples. To check the significance of the mean differences we have used Mann-Whitney's non-parametric test. The analyses have been performed using the deaR package, which runs on R software.

On average, the overall efficiency level for the entity set is extremely high. In the model for CCR, NPL SWs have efficiency levels (0.9039) above the average of 0.8267 obtained by FPL SWs, with a difference of $7.72 \%$.

Considering variable returns (BCC model), i.e., when SWs are compared to others of a similar size, the efficiency increases considerably. The performance of NPL SWs is 0.9498 , also higher than the average of 0.8910 obtained by FPL SWs.

Analyzing the scale efficiency levels for each year, the quotient takes values close to the unit, showing an adequate degree of optimization for level of efficiency when it comes to the scale of operations. In terms of average scale efficiency for NPL SWs (0.9517) score $2.49 \%$ higher than FPL SWs (0.9268). 
Table 2. Differences in means and differences in medians.

\begin{tabular}{|c|c|c|c|c|c|c|}
\hline & & NPL SW & FPL SW & Difference & Z-Statistic & $p$-Value \\
\hline $\begin{array}{c}\text { Technical } \\
\text { Efficiency (CCR) }\end{array}$ & Mean SD Median & 0.90390 .13010 .9544 & 0.82670 .18100 .8607 & 0.0772 & 4.4039 & $0.0000^{* * *}$ \\
\hline $\begin{array}{l}\text { Pure Technical } \\
\text { Efficiency (BCC) }\end{array}$ & Mean SD Median & 0.94980 .11421 .0000 & 0.89100 .16051 .0000 & 0.0588 & 4.4209 & $0.0074^{* * *}$ \\
\hline $\begin{array}{l}\text { Scale Efficiency } \\
\text { (CCR/BCC) }\end{array}$ & Mean SD Median & 0.95170 .07200 .9946 & 0.92680 .10810 .9735 & 0.0249 & 1.95 & 0.0511 * \\
\hline SBM-BCC & Mean SD Median & 0.90300 .15451 .0000 & 0.81340 .23350 .9240 & 0.0896 & 4.4363 & $0.0000^{* * *}$ \\
\hline SBM-CCR & Mean SD Median & 0.72030 .25400 .7629 & 0.68350 .26340 .6778 & 0.0368 & 1.4016 & 0.1615 \\
\hline $\begin{array}{l}\text { Social Efficiency } \\
\text { (BCC) }\end{array}$ & Mean SD Median & 0.80370 .22980 .9205 & 0.71280 .26390 .7033 & 0.0909 & 4.5449 & $0.0000^{* * *}$ \\
\hline $\begin{array}{c}\text { Economic } \\
\text { Efficiency (BCC) }\end{array}$ & Mean SD Median & 0.84510 .18980 .9201 & 0.77710 .23250 .8222 & 0.068 & n3.0688 & $0.0020^{* * *}$ \\
\hline $\begin{array}{l}\text { Total Factor } \\
\text { Productivity } \\
\text { (TFP-BCC) }\end{array}$ & Mean SD Median & 1.02260 .25551 .0000 & 1.04230 .33631 .0000 & -0.0197 & 0.7323 & 0.4666 \\
\hline $\begin{array}{l}\text { Technical } \\
\text { Efficiency } \\
\text { Change } \\
\text { (TEC-BCC) }\end{array}$ & Mean SD Median & 1.01150 .21801 .0000 & 1.00940 .19921 .0000 & 0.0021 & 1.8618 & $0.0627 *$ \\
\hline $\begin{array}{l}\text { Technical Change } \\
\text { (TC-BCC) }\end{array}$ & Mean SD Median & 1.01710 .18630 .9983 & 1.05190 .32251 .0118 & -0.0349 & -0.8114 & 0.4197 \\
\hline
\end{tabular}

Source: Own elaboration. ${ }^{* * *}$ Significance level $\alpha=0.01$; Significance level $\alpha=0.05 ;{ }^{*}$ Significance level $\alpha=0.10$.

Similar results have been obtained when applying the SBM model (both the BCC and CCR versions), NPL SWs having better results in both cases. Note that the differences are not statistically significant for the CCR model.

For the next step, we have calculated social and economic efficiency separately. SWs score lower for social aspects than for economic ones.

Regarding economic efficiency, the average score of NPL SWs is 0.8451 , also higher than that of FPL SWs, at 0.7771 . In spite of being non-profit, unexpectedly, NPL SWs achieve an economic performance score which is $6.08 \%$ higher than that of FPL SWs.

As for social efficiency, the average score for NPL SWs is 0.8037 and 0.7128 for FPL. NPL SWs achieve a social performance score which is $9.09 \%$ higher than that of FPL SWs. The strategy of NPL SWs generates better economic and social results.

In the following step, as you can see in the table above (Table 2), to analyze the change in productivity, we have calculated the Malmquist Productivity Index. The total factor productivity (TFP) of NPL SWs is 1.0226, slightly lower than for SW FPLs, which stands at 1.0423. However, the result is not statistically significant.

As for the two factors in which we can divide TFP, the average Technical Efficiency Change (TEC) of NPL SWs is 1.0115 compared to the average of 1.0094 for SW FPLs. The Technical Change (TC) in NPL SWs is 1.0171 lower than the average of 1.0519 for FPL SWs. However, this difference is not statistically significant for TC while for TCE it is at $10 \%$.

In general, the results discussed above in terms of the median are similar to those obtained with the mean. In short, SWs have more opportunities, in general, to improve efficiency on a social level by obtaining lower scores. NPL SWs score better for both social and economic efficiency whereas in terms of productivity, this is slightly lower in NPL SWs. In addition, the results show that the productivity of both types of SWs is more influenced by external aspects of the organizations, such as changes in public policies or in the economic environment, and this effect is greater in FPLs than in NPLs. For internal factors, the ability to use their own resources to increase efficiency (TEC) leads to low productivity gains, albeit slightly higher in NPLs. 


\subsection{Trend Efficiency Scores: Global, Social and Economic}

Below, we have analyzed temporal evolution for the different types of efficiency in the SW set, differentiating them by entity type (i.e., a for-profit or not-for profit legal status).

Figure 1 reflects total efficiency for the SW set and for subsamples NPL and FPL SW.

Figures 2 and 3 reflect economic and social efficiency.

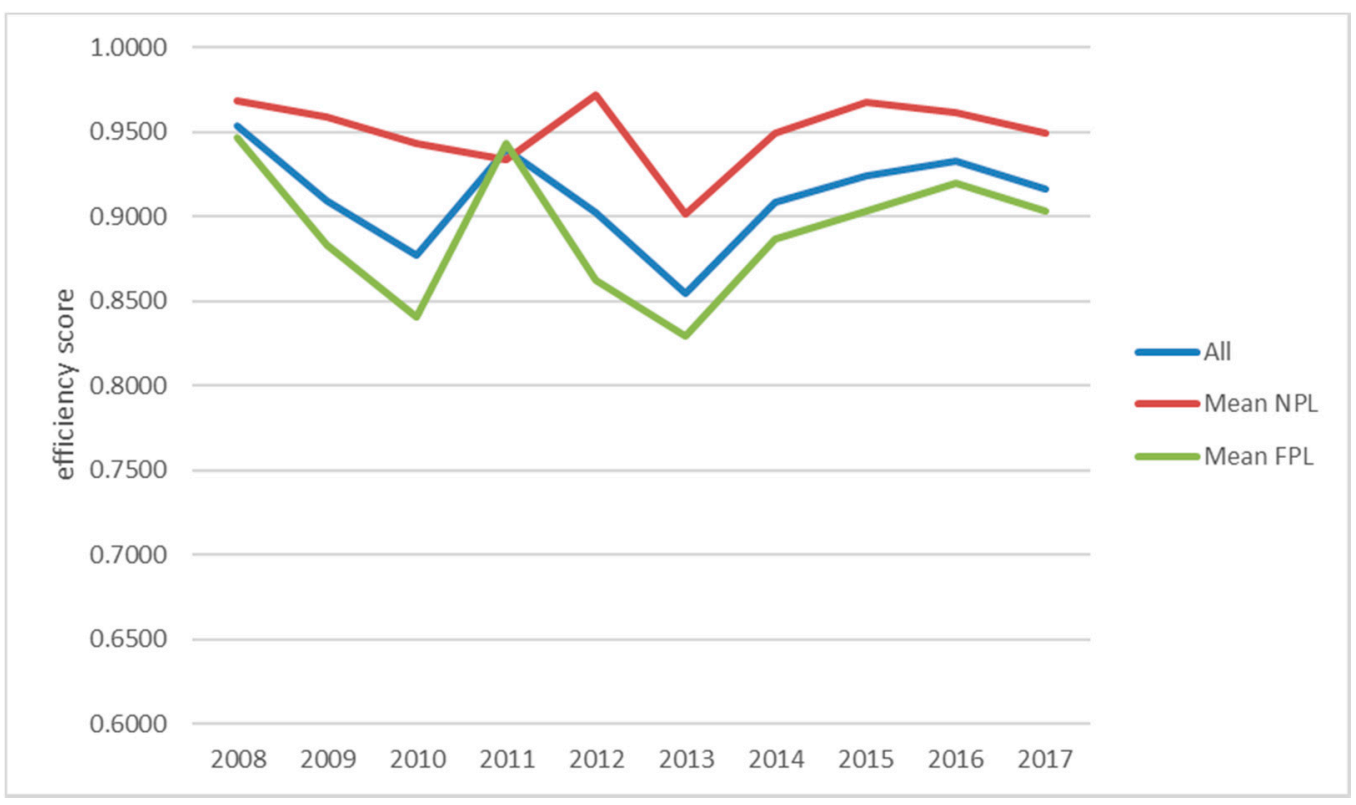

Figure 1. Efficiency BCC, All, NPL and FPL SWs (2008-2017).

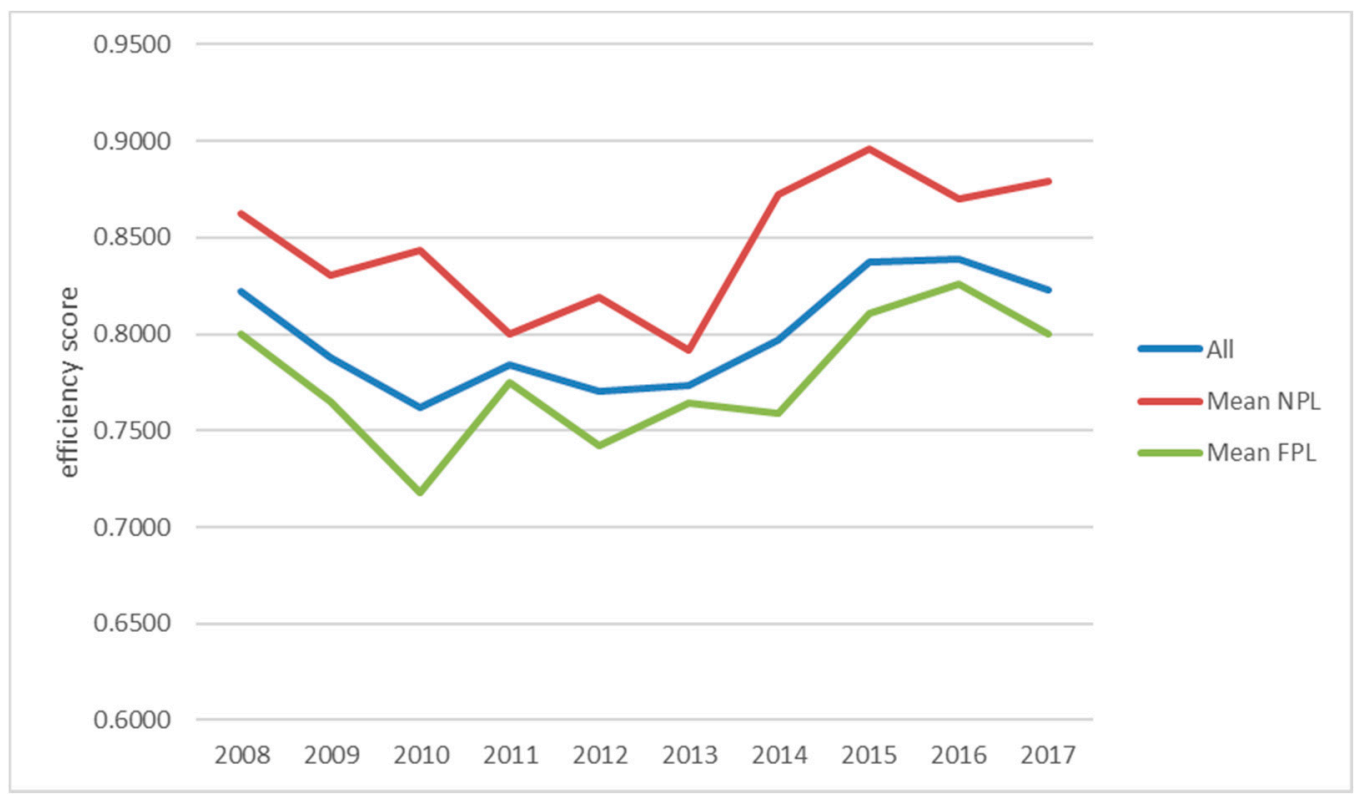

Figure 2. Economic Efficiency BCC, All, NPL and FPL SWs (2008-2017). 


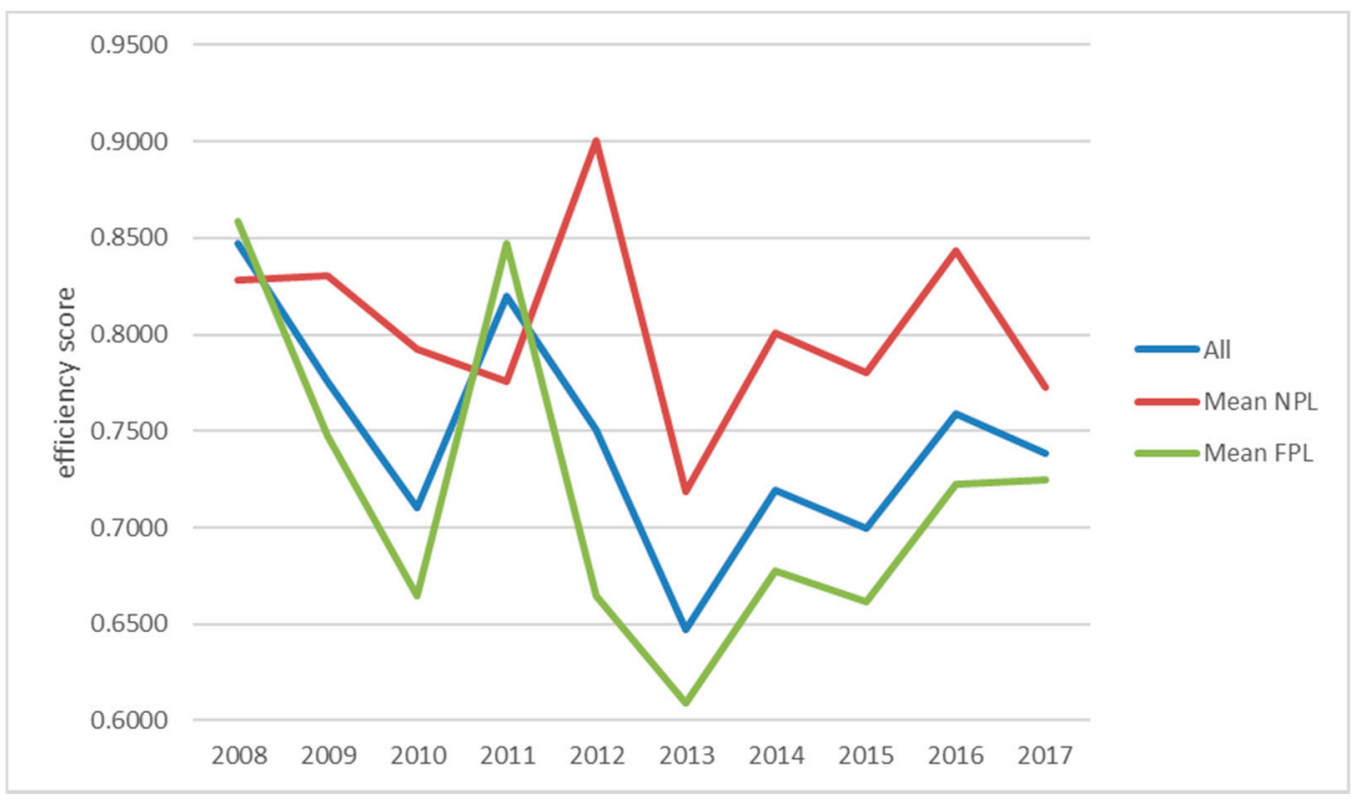

Figure 3. Social Efficiency BCC, All, NPL and FPL SWs (2008-2017).

NPL SWs had better efficiency scores in all of the aspects, not only overall but also socially and economically for all financial years, with the exception of social efficiency in 2011 where it achieved slightly higher values in FPL SWs.

The evolution of these efficiencies was by no means homogeneous. Thus, we have divided the time period into three sub-periods: the financial crisis (2008-2011), a period characterized by uncertainty arising from the slump in subsidies (2012-2013) and the upturn in the economy (2014-2017).

It should be noted that despite the employment crisis and significant cuts in public services, subsidies for SWs increased significantly in 2010 and 2011, although from 2012 onwards there was a very significant reduction in them, with levels remaining stagnant for the rest of the period studied.

During the onset of the financial crisis (2008-2011), both economic (4\%) and social (3\%) efficiency went down in both types of SWs, albeit more strongly in NPL SWs as FPLs saw that economic efficiency had significantly increased by 2011 as a result of increased subsidies. During 2012 and 2013 SWs were subject to great uncertainty arising from the significant decrease in subsidies and turnover alike. Despite this gloomy economic outlook, economic efficiency remained constant, even though it was at the expense of a sharp reduction in social efficiency (totaling $17 \%$ for both financial years), especially in FPLs (24\%). The year 2014 marked the end of the financial crisis in Spain, as it was the first year that GDP and the variation in the number of social security members were positive again in this country. The years 2014, 2015, and 2016 were the first years of economic recovery that resulted in an improvement in company turnover and, although subsidies were still at low levels, they managed to increase their economic efficiency by $7 \%$ and their social efficiency by $11 \%$. During this period, both aspects improved both economically and socially, with efficiency being homogeneous for both types of SWs. In 2017, both economic and social efficiency decreased slightly ( $2 \%$ in both cases). It seems that, in 2017 , a similar situation to the one we saw at the beginning of the crisis whereby economic and social efficiency fell was repeated. Although, in this case, there was no reduction either in turnover or subsidies, which actually went up, operating costs and fixed tangible assets became higher, and the number of disadvantaged employees went down.

\subsection{Quartile Analysis of Global, Social and Economic Efficiency}

Having analyzed the temporal evolution of efficiency and according to the type of entity (NPL-FPL), we have split the sample into three quartiles (upper, mid and lower) to 
find out if the different periods or stages that we have discussed in the previous section affected them in the same way and whether the evolution of social and economic efficiency was homogeneous between them.

The top (Q1) and bottom (Q4) quartiles consist of 22 DMUs each achieving the highest and lowest average global efficiency throughout the study period. The mid (Q2-Q3) quartile consists of 46 DMUs. This division into quartiles allows us to analyze how each of these subgroups behaved during the different stages. The average total efficiency during the study period has been taken into account in order to carry out this split. Since in the upper percentile there are a greater number of SWs (efficiency 1), we have used super-efficiency to perform this division. This approach has been used by others, for example by Staessens et al. [17] and Harrison and Rouse [47], to compare efficiency indicators obtained by DEA.

The results are reflected in Figures 4-6, showing total efficiency, and economic and social efficiency for NPL and FPL.

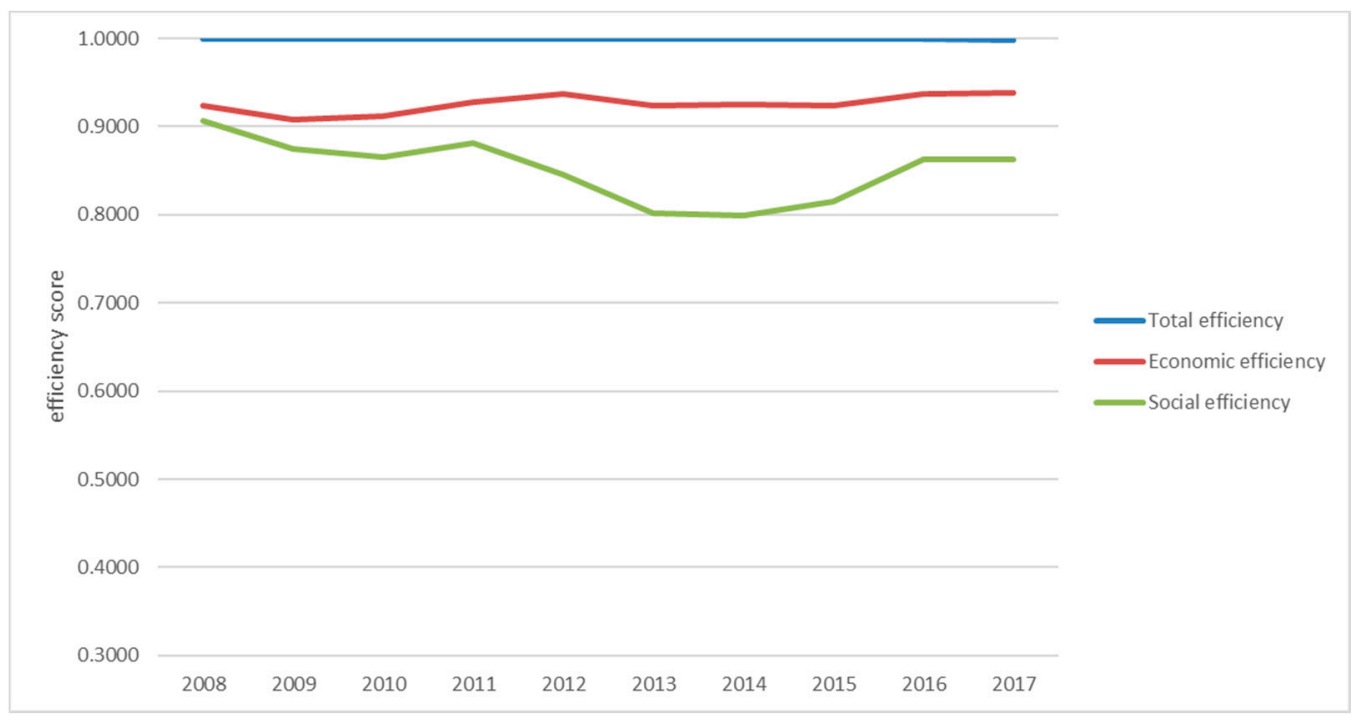

Figure 4. Efficiency Q1 (2008-2017).

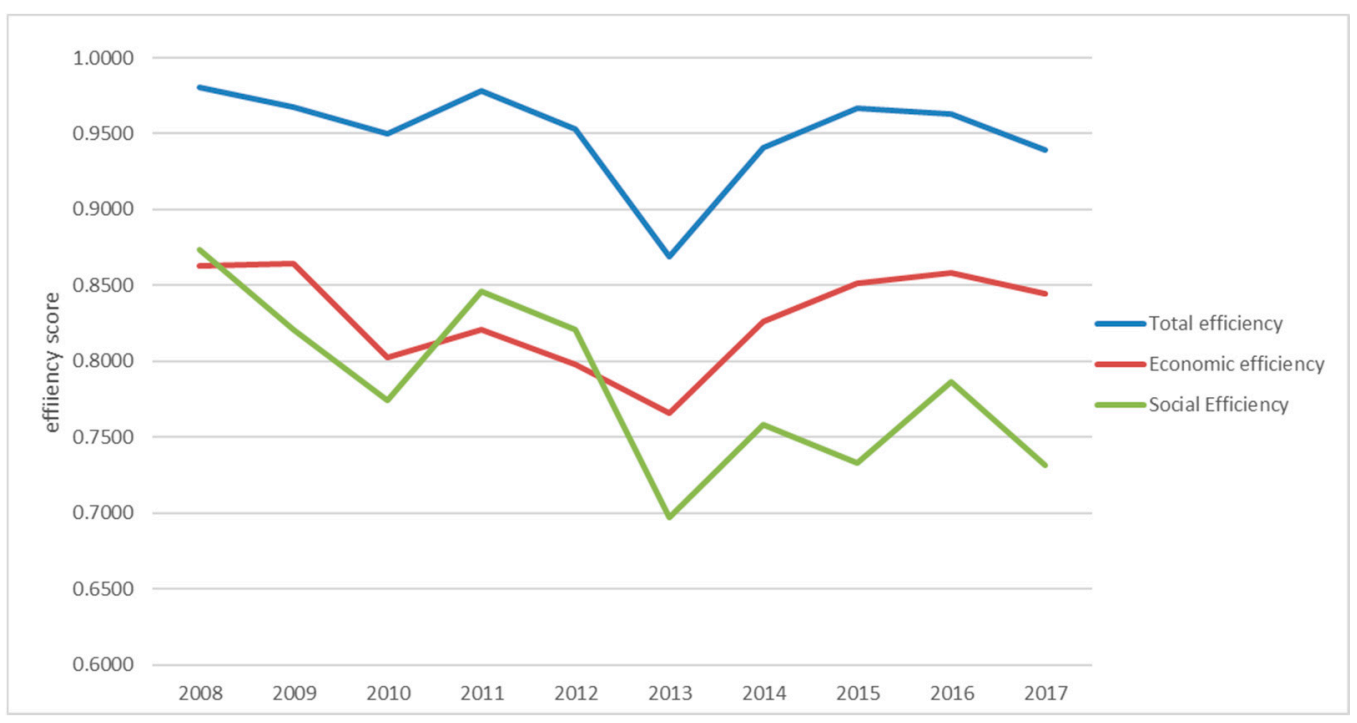

Figure 5. Efficiency Q2-Q3 (2008-2017). 


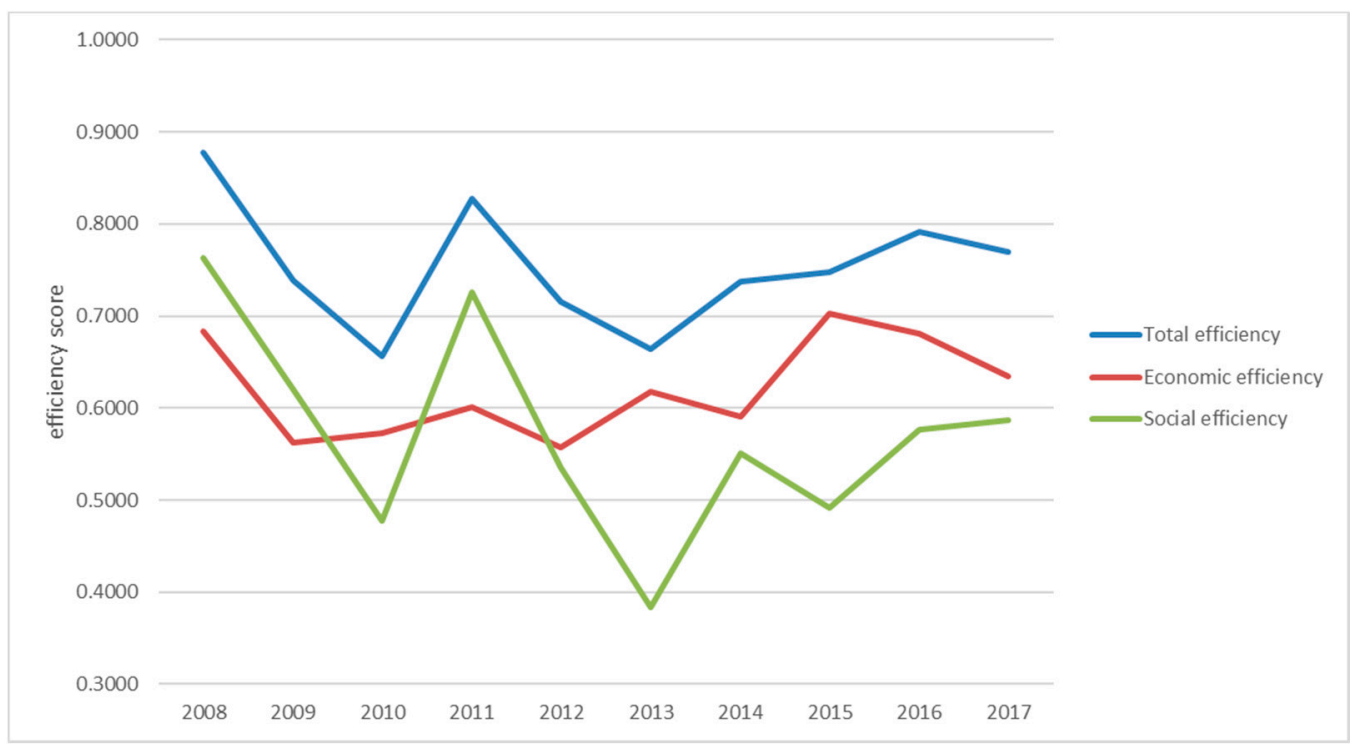

Figure 6. Efficiency Q4 (2008-2017).

As we can see in Table 3, top quartile (Q1) SWs achieved greater efficiency, both socially and economically, than mid and bottom quartiles. To check the significance of the mean differences we have used Mann-Whitney's non-parametric test. We have compared the different quartiles between pairs and all the differences in measurements are significant, except for the social efficiency between the Q2-Q3 and Q1 pairs.

Table 3. Efficiency in top, mid and bottom quartiles.

\begin{tabular}{cccc}
\hline & Q1 & Q2-Q3 & Q4 \\
\hline Total Efficiency & 1 & 0.9508 & 0.7527 \\
Economic Efficiency & 0.9257 & 0.8296 & 0.6203 \\
Social Efficiency & 0.8515 & 0.7841 & 0.5711 \\
\hline
\end{tabular}

Source: own elaboration.

The SWs in the bottom quartile achieved a global efficiency $24.73 \%$ lower than the SWs in the top quartile on average. The SWs in the bottom quartile achieved a social efficiency of only $57.11 \%$ on average, and an economic efficiency of $62.03 \%$.

In addition, despite the distance between the efficiency of the sets studied in Q1 and Q4 in $2008(23.96 \%)$, during the observation period, the gap widened, in 2017 reaching $30.44 \%$. The economic efficiency of bottom quartile SWs decreased by $4.94 \%$ to $63.45 \%$, while that of top quartile SWs increased slightly (1.54\%). Moreover, this lower economic efficiency was not offset by greater social efficiency, the difference between Q1 and Q4 quartiles standing at $28.04 \%$ on average. The difference in social efficiency between the entities of both quartiles in 2008 was $14.3 \%$, which rose to $27.53 \%$ in 2017 .

It can be observed that the initial efficiency differences between the SWs of the different quartiles actually increased not decreased over the study period, both economically and socially.

The SWs in the first quartile managed to maintain, or even slightly increase, their economic efficiency. However, the SWs of the last quartile saw their economic efficiency diminish. As for social efficiency, it decreased slightly for the SWs in the first quartile, but it did so very significantly for the SWs in the last quartile. It is necessary to possess economic strength to achieve adequate social efficiency. Despite the significant initial improvement margin of the SWs in the last quartile, they failed to better their situation.

The SWs in the first quartile maintained much more homogeneity for efficiency, with slight decreases during the crisis that had almost recovered in the years of economic upturn. 


\subsection{The Relationship between Economic and Social Efficiency}

In order to further the knowledge of the relationship between social and economic efficiency, we have proposed parametric analyses among the scores obtained. We have used truncated regression estimation with double-bootstrap and Algorithm II proposed by Simar and Wilson [7]

The estimate has been performed using bootstrap_basic from the deaR package under $\mathrm{R}$ software. Table 4 shows the results of the two estimated models. The first model (Model 1) has economic efficiency as the dependent variable and social efficiency as the independent one. In the second (Model 2), SW profitability explains social efficiency, as measured by the ROA.

Table 4. Regression results comparing Economic Efficiency with Social Efficiency, Algorithm II Simar and Wilson.

\begin{tabular}{cccc}
\hline & Beta & LL & UL \\
\hline & Model 1. Dependent variable: Economic Efficiency \\
\hline Intercept & $-68.7705^{*}$ & -110.3213 & -38.7591 \\
Social Efficiency & -2.1359 & -9.9470 & 2.3238 \\
Sigma & $18.8782^{*}$ & 13.7877 & 24.1519 \\
\hline \multicolumn{4}{c}{ Model 2. Dependent variable: Social Efficiency } \\
\hline Intercept & $-117.4499^{*}$ & -177.2693 & -73.5670 \\
ROA & $-0.5551^{*}$ & -0.8706 & -0.3238 \\
Sigma & $22.9101^{*}$ & 16.6053 & 29.4268 \\
\hline
\end{tabular}

Source: Own elaboration. Note: * Significant at 5\%. LL lower level, UL upper level.

In these models the positive beta coefficients indicate an increase in inefficiency i.e., a decrease in efficiency, whereas a positive coefficient shows the opposite (in this methodology, if the efficiency score is 1 , it means maximum efficiency, and if it is greater than 1 , inefficiency).

In Model 1, whereby economic efficiency is the dependent variable and social efficiency the independent one, we see that it is not significant and therefore we believe that social efficiency does not significantly affect economic efficiency. It has been tested for a significance level of $10 \%$ but it is not significant either.

In the section above we have pointed out that it is necessary to have economic strength to obtain adequate social efficiency. Therefore, Model 2 analyzes the relationship between social efficiency and profitability of SWs, measured by ROA, as we believe that economic success is fundamental in order to maintain sustainability as its social objective. Statistically significant influence has been confirmed; economic profit (ROA) increases social efficiency and is an enabler of its social activities. However, we have found no evidence to support a similar reinforcement mechanism between social and economic efficiency.

\section{Conclusions}

This study furthers knowledge about the performance of sheltered workshops, which represent a type of social enterprise and are considered to be hybrid organizations. We use the DEA methodology to calculate the total, social and economic efficiency scores.

The empirical analysis of the wide range of types of SWs existing in Galicia (Spain) between 2008 and 2017 indicates that they dealt with changes in public policies and economic uncertainty differently. It is the not-for-profit SWs that achieved better social and economic performance over time. Improved economic behavior in the crisis period (2008-2014) allowed them to cope with the era of economic policy changes and the drop in grants. These types of SWs do not present, as we might expect, a more fragile economic profile than for-profit SWs. This same conclusion has been drawn from the comparison by quartiles, in such a way that the SWs that started off with a better economic situation managed to achieve greater efficiency both economically and socially in the period under the spotlight. The least efficient SWs (bottom quartile) were significantly affected by the 
economic crisis and uncertainty in grant-related public policies, especially at the social level. Although, in recent years, once the crisis had passed, their economic and social efficiency was enhanced, this was not enough to near the conditions that had been in place initially (i.e., 2008), nor did it narrow their lead with the SWs of the top quartile.

In short, the increasing pressure for SWs to be less reliant on public aid resulted in a decrease in their social efficiency, particularly for the for-profit SWs and those located in the bottom quartiles.

It is the not-for profit SWs that managed to maintain a greater efficiency average overall, both socially and economically. Their extensive social proactiveness positively influenced their social and economic performance and the absence of profit was a protective barrier to the mission drift. A similar situation can be witnessed in the SWs located in the top quartile: they continued to achieve significant social efficiency even if they had reached high levels of economic performance. The greatest economic strength in times of crisis gave them a competitive advantage that allowed them to better themselves in economic and social efficiency in later periods.

We can confirm that social efficiency, as measured by people with disabilities and personal and social adjustment services, presents a positive relationship with SW profitability measured by its return on assets (ROA), as proposed by the shared-value perspective, which means that neither of the aspects are in conflict. Combining social and economic goals has allowed these enterprises to run in an efficient way to fulfill disabled people's requirements while achieving financial viability. To continue forth on their social mission, while they develop their conventional commercial activity, it is paramount that they resolve their social and economic inefficiencies so as to run their business in an ethical and responsible manner with all their stakeholders.

More specifically, we feel that these conclusions could help guide policymakers in their decision-making processes. They could use this approach to achieve greater efficiency, reallocating resources to SWs which have better social and economic management and, additionally, to assess how their policies have affected different types of entities.

Sheltered workshops have high levels of social and economic efficiency and both objectives have been compatible. However, their social efficiency decreases over time, so policymakers must try to promote the social function of these institutions, especially for not-for profit organizations, as they are vital for the development of disabled people.

Finally, it should be noted that different social aspects, particularly those of a qualitative nature, could not be gathered in our model, as the data was not available. Despite this, we consider that the model presented includes the core factors for assessing the social contribution of SWs.

Author Contributions: Conceptualization, J.M.M.-S.; methodology, J.M.M.-S., M.-C.L.-P., and C.L.-A.; software, J.M.M.-S., and M.-C.L.-P.; validation, J.M.M.-S., M.-C.L.-P., J.T.-M., and C.L.-A.; formal analysis, J.M.M.-S., M.-C.L.-P., J.T.-M., and C.L.-A.; investigation J.M.M.-S., M.-C.L.-P., J.T.-M., and C.L.-A.; resources, J.M.M.-S., M.-C.L.-P., J.T.-M., and C.L.-A.; data curation, J.T.-M.; writing-original draft preparation, J.M.M.-S., M.-C.L.-P., and C.L.-A.; writing-review and editing, J.M.M.-S. and M.-C.L.-P.; visualization, J.M.M.-S., M.-C.L.-P., J.T.-M., and C.L.-A.; supervision, J.M.M.-S., M.-C.L.-P., and C.L.-A.; project administration, J.M.M.-S. and M.-C.L.-P.; funding acquisition, J.M.M.-S., M.-C.L.-P., and C.L.-A. All authors have read and agreed to the published version of the manuscript.

Funding: We gratefully acknowledge financial support provided by the Consellería de Cultura, Educación e Universidade (Xunta de Galicia) with reference ED431C 2020/18, co-funded by the European Regional Development Fund (ERDF/FEDER) within the period 2020-2023.

Institutional Review Board Statement: Not applicable.

Informed Consent Statement: Not applicable.

Data Availability Statement: The data presented in this study are available on request from the corresponding author. 
Conflicts of Interest: The authors declare no conflict of interest. The funders had no role in the design of the study; in the collection, analyses, or interpretation of data; in the writing of the manuscript, or in the decision to publish the results.

\section{References}

1. Mongelli, L.; Rullani, F.; Ramus, T.; Rimac, T. The Bright Side of Hybridity: Exploring How Social Enterprises Manage and Leverage Their Hybrid Nature. J. Bus. Ethics 2019, 159, 301-305. [CrossRef]

2. Gali, N.; Niemand, T.; Shaw, E.; Hughes, M.; Kraus, S.; Brem, A. Social entrepreneurship orientation and company success: The mediating role of social performance. Technol. Forecast. Soc. Chang. 2020, 160, 120230. [CrossRef]

3. Saebi, T.; Foss, N.J.; Linder, S. Social Entrepreneurship Research: Past Achievements and Future Promises. J. Manag. 2019, 45, 70-95. [CrossRef]

4. Ebrahim, A.; Rangan, V.K. What Impact? A Framework for Measuring the Scale and Scope of Social Performance. Calif. Manag. Rev. 2014, 56, 118-141. [CrossRef]

5. Stevens, R.; Moray, N.; Bruneel, J.; Clarysse, B. Attention allocation to multiple goals: The case of for-profit social enterprises: Attention Allocation to Multiple Goals. Strateg. Manag. J. 2015, 36, 1006-1016. [CrossRef]

6. Bagnoli, L.; Megali, C. Measuring Performance in Social Enterprises. Nonprofit Volunt. Sect. Q. 2011, 40, 149-165. [CrossRef]

7. Simar, L.; Wilson, P.W. Estimation and inference in two-stage, semi-parametric models of production processes. J. Econom. 2007, 136, 31-64. [CrossRef]

8. European Commission European Disability Strategy 2010-2020: A Renewed Commitment to a Barrier-Free Europe. Communication from the Commission to the European Parliament, the Council, the European Economic and Social Committee and the Committee of the Regions. COM(2010) 636 Final. Brussels. Available online: https:/ / ec.europa.eu/eip/ageing/standards/ general/general-documents/european-disability-strategy-2010-2020_en (accessed on 22 September 2020).

9. INE El Empleo de las Personas con Discapacidad. Available online: https://www.ine.es/CDINEbase/consultar.do?mes= \&operacion=El+empleo+de+las+personas+con+discapacidad\&id_oper=Ir (accessed on 3 February 2020).

10. Herrero Montagud, M.; Monzón Campos, J.L. Identificación y análisis de las características identitarias de la empresa social europea: Aplicación a la realidad de los Centros Especiales de Empleo de la economía española. CIRIEC Esp. Rev. Econ. Pública Soc. Coop. 2016, 87, 295-326. [CrossRef]

11. Defourny, J.; Nyssens, M. The EMES approach of social enterprise in a comparative perspective. Soc. Enterp. Third Sect. Chang. Eur. Landsc. Comp. Perspect. 2014, 12, 42-65.

12. Battilana, J.; Sengul, M.; Pache, A.-C.; Model, J. Harnessing productive tensions in hybrid organizations: The case of Work Integration Social Enterprises. Acad. Manag. J. 2015, 58, 1658. [CrossRef]

13. Pache, A.-C.; Santos, F. Inside the Hybrid Organization: Selective Coupling as a Response to Competing Institutional Logics. Acad. Manag. J. 2013, 56, 972-1001. [CrossRef]

14. Battilana, J.; Dorado, S. Building Sustainable Hybrid Organizations: The Case of Commercial Microfinance Organizations. Acad. Manag. J. 2010, 53, 1419-1440. [CrossRef]

15. Canales, R. Weaving Straw into Gold: Managing Organizational Tensions between Standardization and Flexibility in Microfinance. Organ. Sci. 2014, 25, 1-28. [CrossRef]

16. Ebrahim, A.; Battilana, J.; Mair, J. The governance of social enterprises: Mission drift and accountability challenges in hybrid organizations. Res. Organ. Behav. 2014, 34, 81-100. [CrossRef]

17. Staessens, M.; Kerstens, P.J.; Bruneel, J.; Cherchye, L. Data Envelopment Analysis and Social Enterprises: Analysing Performance, Strategic Orientation and Mission Drift. J. Bus. Ethics 2018, 159, 325-341. [CrossRef]

18. Bellostas, A.J.; López-Arceiz, F.J.; Mateos, L. Social Value and Economic Value in Social Enterprises: Value Creation Model of Spanish Sheltered Workshops. Voluntas 2016, 27, 367-391. [CrossRef]

19. Lee, P.; Seo, Y.W. Directions for Social Enterprise from an Efficiency Perspective. Sustainability 2017, 9, 1914. [CrossRef]

20. Arena, M.; Ciceri, N.D.; Terzi, S.; Bengo, I.; Azzone, G.; Garetti, M. A state-of-the-art of industrial sustainability: Definitions, tools and metrics. Int. J. Prod. Lifecycle Manag. 2009, 4, 207. [CrossRef]

21. Wilson, F.; Post, J.E. Business models for people, planet (\& profits): Exploring the phenomena of social business, a market-based approach to social value creation. Small Bus. Econ. 2013, 40, 715-737. [CrossRef]

22. Copestake, J. Mainstreaming Microfinance: Social Performance Management or Mission Drift? World Dev. 2007, 35, 1721-1738. [CrossRef]

23. Dacin, M.T.; Dacin, P.A.; Tracey, P. Social Entrepreneurship: A Critique and Future Directions. Organ. Sci. 2011, 22, 1203-1213. [CrossRef]

24. Stevens, R.; Moray, N.; Bruneel, J. The Social and Economic Mission of Social Enterprises: Dimensions, Measurement, Validation, and Relation. Entrep. Theory Pract. 2015, 39, 1051-1082. [CrossRef]

25. Clifford, J.; Hehenberger, L.; Fantini, M. Proposed Approaches to Social Impact Measurement in European Commission Legislation and in Practice Relating to: EuSEFs and the EaSI; GECES Sub-Group on Impact Measurement, Publications Office: Brussels, Belgium, 2014.

26. Doherty, B.; Haugh, H.; Lyon, F. Social Enterprises as Hybrid Organizations: A Review and Research Agenda. Int. J. Manag. Rev. 2014, 16, 417-436. [CrossRef] 
27. Gelashvili, V.; Camacho-Miñano, M.D.M.; Segovia-Vargas, M.J. A study of the economic and financial analysis for social firms: Are they really businesses? Rev. Contab. Span. Account. Rev. 2020, 23, 139-147. [CrossRef]

28. Arceiz, F.J.L.; Moles, L.M.; Vera, J.O.; Perales, I.S.; Pérezgrueso, A.J.B.; Alijarde, M.I.B. Actividades e impactos de la empresa social. Estudio de los Centros Especiales de Empleo aragoneses. CIRIEC España Rev. Econ. Pública Soc. Coop. 2014, 81, $217-239$.

29. Manzano Martín, M.I.; Redondo Martín, M.N.; Robles Paramio, M.P. Los centros especiales de empleo en Castilla y León, 2007-2013: Efectos de la crisis en función de la personalidad jurídica que adoptan. REVESCO Rev. Estud. Coop. 2016, 122, 191-218. [CrossRef]

30. López-Penabad, M.-C.; Maside-Sanfiz, J.M.; Torrelles-Manent, J. Análisis económico y social de los centros especiales de empleo: Un estudio en Galicia. REVESCO Rev. Estud. Coop. 2019, 132, 169-194. [CrossRef]

31. Spieth, P.; Schneider, S.; Clauß, T.; Eichenberg, D. Value drivers of social businesses: A business model perspective. Long Range Plann. 2019, 52, 427-444. [CrossRef]

32. Gutiérrez-Nieto, B.; Serrano-Cinca, C.; Molinero, C.M. Microfinance institutions and efficiency. Omega 2007, 35, 131-142. [CrossRef]

33. Charnes, A.; Cooper, W.W.; Rhodes, E. Measuring the efficiency of decision making units. Eur. J. Oper. Res. 1978, 2, 429-444. [CrossRef]

34. Belu, C. Ranking corporations based on sustainable and socially responsible practices. A data envelopment analysis (DEA) approach. Sustain. Dev. 2009, 17, 257-268. [CrossRef]

35. Mousavi, M.M.; Ouenniche, J.; Tone, K. A comparative analysis of two-stage distress prediction models. Expert Syst. Appl. 2019, 119, 322-341. [CrossRef]

36. Banker, R.D.; Charnes, A.; Cooper, W.W. Some models for estimating technical and scale inefficiencies in Data Envelopment Analysis. Manag. Sci. 1984, 30, 1078-1092. [CrossRef]

37. Tone, K. A slacks-based measure of efficiency in data envelopment analysis. Eur. J. Oper. Res. 2001, 130, 498-509. [CrossRef]

38. Kohl, S.; Schoenfelder, J.; Fügener, A.; Brunner, J.O. The use of Data Envelopment Analysis (DEA) in healthcare with a focus on hospitals. Health Care Manag. Sci. 2019, 22, 245-286. [CrossRef] [PubMed]

39. Grieco, C.; Michelini, L.; Iasevoli, G. Measuring Value Creation in Social Enterprises: A Cluster Analysis of Social Impact Assessment Models. Nonprofit Volunt. Sect. Q. 2015, 44, 1173-1193. [CrossRef]

40. Arena, M.; Azzone, G.; Bengo, I. Performance Measurement for Social Enterprises. Volunt. Int. J. Volunt. Nonprofit Organ. 2015, 26, 649-672. [CrossRef]

41. Rawhouser, H.; Cummings, M.; Newbert, S.L. Social Impact Measurement: Current Approaches and Future Directions for Social Entrepreneurship Research. Entrep. Theory Pract. 2019, 43, 82-115. [CrossRef]

42. Retolaza, J.L.; San-José, L.; Araujo, A. La Eficiencia como reto de las Empresas de Inserción. REVESCO Rev. Estud. Coop. 2014, 115, 159-185. [CrossRef]

43. Marcuello, C. Análisis de la conducta de la eficiencia de las organizaciones no gubernamentales españolas. Econ. Coop. Desarro. 1999, 778, 181-196.

44. Martínez Franco, C.M.; Guzmán Raja, I. Medida de la eficiencia en entidades no lucrativas: Un estudio empírico para fundaciones asistenciales. Rev. Contab. 2014, 17, 47-57. [CrossRef]

45. Basharat, B.; Hudon, M.; Nawaz, A. Does Efficiency Lead to Lower Prices? A New Perspective from Microfinance Interest Rates: Efficiency and Interest Rates in Microfinance. Strateg. Chang. 2015, 24, 49-66. [CrossRef]

46. Gutiérrez-Nieto, B.; Serrano-Cinca, C.; Mar Molinero, C. Social efficiency in microfinance institutions. J. Oper. Res. Soc. 2009, 60, 104-119. [CrossRef]

47. Harrison, J.; Rouse, P. DEA and Accounting Performance Measurement. In Handbook of Operations Analytics Using Data Envelopment Analysis; International Series in Operations Research \& Management, Science; Hwang, S.-N., Lee, H.-S., Zhu, J., Eds.; Springer: Boston, MA, USA, 2016; Volume 239, pp. 385-412. ISBN 9781489977038. 